\title{
Improved Detection of Interannual Cloud Variability over the Southern Hemisphere Using Legacy Satellites
}

\author{
Shay LiU AND PAul W. STATEN \\ Indiana University Bloomington, Bloomington, Indiana \\ BRIAN H. KAHN \\ Jet Propulsion Laboratory, California Institute of Technology, Pasadena, California
}

(Manuscript received 9 October 2019, in final form 22 May 2020)

\begin{abstract}
Shifts in deep tropical convection and midlatitude jet streams both manifest themselves in high cloud anomalies. Such anomalies may play a significant role in local to global climate processes. This work investigates how high cloud properties covary with two primary interannual modes of variability in the Southern Hemisphere (SH): El Niño-Southern Oscillation (ENSO) and the southern annular mode (SAM). In contrast to several recent studies that utilize the latest remote sensing datasets (e.g., CloudSat), we employ a novel combination of imager and sounder data from legacy satellite instruments. Using these legacy data, we confirm the poleward shift of high cloud fields in the SH midlatitudes with SAM seen in other recent studies and characterize the opposing impacts of SAM and ENSO on the South Pacific convergence zone and Southern Hemisphere storm tracks. Furthermore, we demonstrate that the standard deviation of brightness temperature data from the window channel acts as a surrogate for high cloud fraction in the tropics and midlatitudes. Our results reconcile apparent differences in recent studies and suggest that brightness temperature standard deviations are climate relevant, in addition to being largely insensitive to instrument calibration.
\end{abstract}

\section{Introduction}

Clouds are both modulators and indicators of climate change. Clouds influence the climate through their radiative and thermodynamic effects, while the internal climate variability changes the dynamical and thermodynamical environment in which clouds form. These internal modes of variability are expected to be perturbed in a warming climate (Lu et al. 2007; Held and Soden 2006; Yin 2005; Rivière 2011; Boucher et al. 2013). Two particular modes that are expected to change include the southern annular mode (SAM) and El NiñoSouthern Oscillation (ENSO), a coupled oscillation of oceanic and atmospheric heat content and heat and convection (Ceppi and Hartmann 2015; Klein et al. 1999). Both of these oscillations are manifest as changes in cloud height and cloud fraction (Bender et al. 2012; Grise et al. 2013; Norris et al. 2016; Eastman and Warren 2013; Li et al. 2014). In middle latitudes, during the positive phase of the SAM, high clouds associated with

Corresponding author: Shay Liu, xuecliu@iu.edu the storm tracks shift poleward (Thompson and Wallace 2000; Fyfe 2003; Gillett et al. 2006). In lower latitudes, during El Niño years (the positive phase of ENSO), an equatorward shift in the subtropical jets and Hadley cell edges (Seager et al. 2003; Lu et al. 2008) manifests as an equatorward shift in high clouds in the subtropics, and the anomalously weak Walker circulation as an eastward shift in high clouds in the tropical Pacific (Radley et al. 2014; Kiladis and van Loon 1988).

Exactly how high and how far clouds shift in response to climate variability and change is difficult to tell. Part of the challenge is that clouds are pathologically difficult to accurately characterize globally for an extended period of time; every cloud dataset has its shortcomings. Weather station data, used in Eastman and Warren (2013), are confined to local observations. The International Satellite Cloud Climatology Project (ISCCP) dataset, used in Bender et al. (2012), Grise et al. (2013), and Norris et al. (2016), utilizes a mixture of geostationary and polar-orbiting satellite data (Schiffer and Rossow 1985; Rossow and Schiffer 1991, 1999), inheriting 
weaknesses of both (Evan et al. 2007) —in particular the high viewing angles of geostationary observations. This requires detrending and other regressions to remove the myriad sources of uncertainty (Norris and Evan 2015). CloudSat and the Cloud-Aerosol Lidar and Infrared Pathfinder Satellite Observations (CALIPSO), which can vertically resolve clouds (see $\mathrm{Li}$ and Thompson 2016, hereafter L16), were launched in 2006, and are thus limited to short-term cloud studies. The Pathfinder Atmospheres-Extended (PATMOS-x) dataset makes use of Advanced Very High Resolution Radiometer (AVHRR) instruments onboard polar-orbiting NOAA satellites in order to produce a climate data record (Norris and Evan 2015; Norris et al. 2016), but has only two thermal channels and thus lacks sufficient thermal infrared information. Reanalyses rely on cloud parameterizations, and thus contain some of the same biases that plague general circulation models (Naud et al. 2014). These shortcomings hamper studies of clouds and climate variability, particularly on longer time scales.

In the present study, we make use of a novel dataset created by Staten et al. (2016, hereafter S16). With the long-term goal of creating an improved long-term cloud dataset, S16 combine visible and infrared data from legacy satellites into a gridded dataset containing brightness temperature $\left(T_{b}\right)$ statistics from each High Resolution Infrared Radiometer Sounder (HIRS) channel, binned by cloud type as determined using AVHRR (Thomas et al. 2004). S16 suggest that cloud-typed $T_{b}$ statistics may aid the intercalibration of sounder data. They also note that the standard deviation of $T_{b}\left[\sigma\left(T_{b}\right)\right]$ in the eastern Pacific increases with high-cloud anomalies during an El Niño year over the eastern Pacific, and that the changes in $\sigma\left(T_{b}\right)$ exceed intersatellite differences, suggesting that $\sigma\left(T_{b}\right)$ values may be useful for the study of interannual climate variability.

The objectives of the current work are twofold: 1) to demonstrate the capability of the combined imagersounder data for characterizing interannual variability, with an emphasis on $\sigma\left(T_{b}\right)$ as a proxy for high cloud fraction, and 2) to characterize the cloud variations associated with two modes of variability in Southern Hemispheric tropics and midlatitudes. We find that $\sigma\left(T_{b}\right)$ helps to validate AVHRR cloud types, and extend the results of S16, showing that such data show promise for long-term climate studies globally. We leverage $\sigma\left(T_{b}\right)$ to help characterize cloud variability, broadly confirming the spatial cloud fraction response to the southern annular mode shown in earlier work done using CloudSat, ISCCP, and reanalyses, and differentiating between the interannual variations and observed trends in cloud fraction. The remainder of this paper is arranged as follows. In section 2, we summarize the methods of S16 and the data used in our study, including reanalyses and modes of variability. In section $3 \mathrm{~b}$, we illustrate the utility of $\sigma\left(T_{b}\right)$ as a metric of high cloud fraction, and then in sections $3 c(1)$ and $3 c(2)$, we present and discuss the results of our regression analysis for SAM and for ENSO before summarizing and concluding in section 4 . In the appendix, we take a closer look at a meridional dipole from L16.

\section{Data and methods}

\section{a. Climate indices}

We examine the changing cloud statistics associated with two modes of variability: the southern annular mode (SAM), and the multivariate ENSO index (MEI). We primarily use the Marshall station-based SAM index, which is measured as the zonal sea level pressure difference between several stations at $40^{\circ} \mathrm{S}$ and $65^{\circ} \mathrm{S}$ (Marshall 2003). We also perform our analysis using SAM data calculated from the Japanese 55-Year Reanalysis (JRA-55) (Japan Meteorological Agency 2015), following Thompson and Woodworth (2014) and Thompson and $\mathrm{Li}$ (2015), and find similar results with either SAM dataset. The MEI is the first principal component of variations in six meteorological variables drawn from International Comprehensive OceanAtmosphere Dataset (ICOADS) (Wolter 1987; Wolter and Timlin 1993, 1998). Our results are similar to the central Pacific and eastern Pacific Niño indices (not shown) from the Australian Bureau of Meteorology.

\section{b. Reanalyses}

The inclusion of reanalysis data in this study serves three purposes. First, we use reanalyses to calculate climate indices. Second, the Clouds from AVHRRExtended (CLAVR-x) cloud retrievals use reanalysis data as auxiliary input. Third, as described in the appendix, we use reanalysis cloud fraction data to reconcile results from several studies of cloud-climate variability.

- JRA-55: We use the SAM index from JRA-55 to validate the Marshall index, as described previously.

- NCEP: Processing of AVHRR imager data requires ancillary data, which we draw from the National Centers for Environmental Prediction (NCEP)-National Center for Atmospheric Research (NCAR) Reanalysis 1 (NNR) (S16; Kalnay et al. 1996). Other reanalyses may be used, but for a study of interannual variability, the choice is not critical (Foster et al. 2016). 


\section{c. Satellite data}

Ideally, a climate dataset needs to be "spectrally broad, spectrally resolved, and traceable to absolute standards" (S16, p. 1519; see also Anderson et al. 2004). Some of the longest cloud property datasets available include ISCCP, PATMOS-x, and HIRS. The issues with ISCCP have been summarized in section 1 . The PATMOS-x climate data record (CDR) (Foster and Heidinger 2013; Heidinger et al. 2014) is built on top of the AVHRR data record alone, providing subpixel level of cloud characterization with radiances from a handful of visible channels. The High-Resolution Infrared Sounder (HIRS), on the other hand, supplies longwave brightness temperature sounding data, and is able to detect clouds such as nighttime clouds and optically thin cloud types (e.g., thin cirrus), which are typically a challenge for imagers like AVHRR (Wylie et al. 2005; Heidinger et al. 2016; Menzel et al. 2016). The interpolated dataset in the present study makes use of both AVHRR and HIRS data from one of the most recent and longest running polar-orbiting weather satellites housing both instruments - the European Organisation for the Exploitation of Meteorological Satellites (EUMETSAT) $M e t O p-A$. While HIRS and AVHRR have flown continuously in a nearly identical configuration since 1978, we focus on data from $\mathrm{Met} O p$ - $A$ here because $\mathrm{Met} O p$ - $A$ has operated continuously since 2007, producing roughly two complete maps of Earth per day. During this time it has expended fuel to maintain a constant equatorial crossing time, experienced little instrument degradation, and overlapped with numerous other instruments, including CloudSat and CALIPSO. We use instantaneous data from $M e t O p$ - $A$ spanning 2007-16. The data we use are documented detail below.

AVHRR observes the planet with a spatial resolution of $1 \mathrm{~km} \times 1 \mathrm{~km}$ at nadir at five spectral channels centered at $0.63,0.86,3.74,10.8$, and $12 \mu \mathrm{m}$-one visible channel, one near-infrared channel, and three other infrared channels, including two thermal infrared. Original data are retained every third line along-track and averaged every four of five adjacent samples along the scan line into a global area coverage (GAC) dataset of $4 \mathrm{~km} \times 4 \mathrm{~km}$ (Frey et al. 1996). We calculate the cloud types from the CLAVR-x postprocessing routine (Thomas et al. 2004) using the daytime only GAC AVHRR data. For consistency with other studies, we partition clouds into ISCCP cloud-top pressure thresholds, labeling our clouds as follows: "high" (cloud-top pressures < 440 hPa), "middle" (cloudtop pressures between 440 and $680 \mathrm{hPa}$ ), "low" (cloud-top pressures $>680 \mathrm{hPa}$ ), and "clear." Our discussion in this paper focuses on high clouds.
HIRS has 19 infrared channels between 3.76 and $14.95 \mu \mathrm{m}$ that sample the whole troposphere discretely (Wylie et al. 1994; Li et al. 2000). MetOp-A houses HIRS version 4 , which has a spatial footprint with a diameter of $10 \mathrm{~km}$. For this study, we focus on HIRS brightness temperatures from the window channel (channel 8, centered at $11.11 \mu \mathrm{m})$.

\section{d. The stitching method}

We calculate gridded cloud type statistics following S16. We refer the reader to their work for more detail but summarize the methodology here.

We first interpolate retrieved cloud types from CLAVR-x onto the larger HIRS footprints. To do so, we consider all of the CLAVR-x pixels that intersect a given HIRS footprint and assign each CLAVR-x pixel a fraction of the HIRS footprint based on empirical results in S16. If at least $90 \%$ of the HIRS footprint is covered by the same CLAVR-x cloud type, that footprint is assigned that cloud type. Otherwise, the pixel is marked as "mixed." To analyze statistics beyond the mean, we perform a single-pass moment calculation, which works by converting $T_{b}$ data into a $T_{b}$ histogram (with a $2.5-\mathrm{K}$ bin spacing) and calculating the statistics from that histogram (Choi and Sweetman 2010). This is done for each point in space and time, with a spatial resolution of $2^{\circ} \times 2^{\circ}$. Statistics can then be calculated for arbitrary regions and arbitrary time periods by adding the histograms together and recalculating the first four moments from the resulting $T_{b}$ histogram. In this study, we focus on the first two statistical moments, namely the mean brightness temperatures [hereafter $\mu\left(T_{b}\right)$ ] and the standard deviation of the brightness temperatures [hereafter $\sigma\left(T_{b}\right)$ ] during boreal winter (December-February; see Fig. 1), when the two modes of variability are both strongest.

\section{e. Statistical treatment and regression}

To examine the cloud statistics associated with each major mode of variability, we regress the gridded cloud statistics onto time series for each mode of variability. Prior to this regression, however, we 1) resample the monthly data into seasonal mean data, 2) remove the seasonal cycle from the seasonal mean cloud data and from the climate indices, 3) remove the linear trends from each dataset, and 4) standardize the climate indices. The cloud statistics we project onto the SAM and ENSO indices include 1) cloud fraction (hereafter CF) for each ISCCP cloud type, 2) $\mu\left(T_{b}\right)$ for each cloud type and HIRS channel, and 3) $\sigma\left(T_{b}\right)$ for each cloud type and HIRS channel. We perform all of these regressions for gridded $M e t O p-A$ data. We also repeat the cloud 
(a) DJF High Cloud Fraction (HCF)

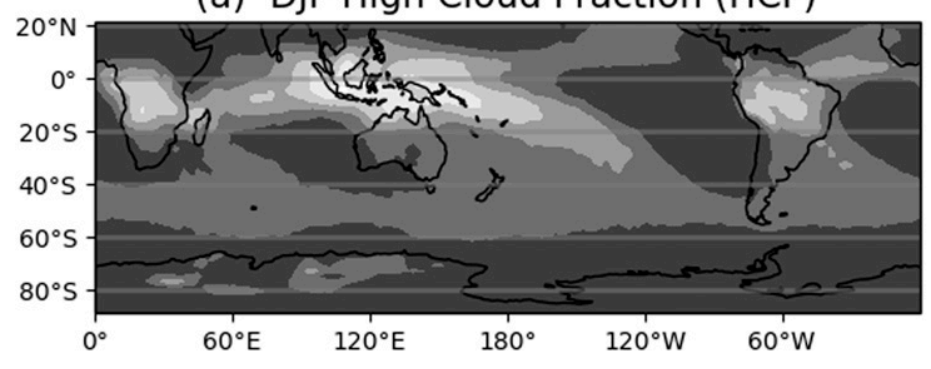

(b) DJF High Cloud $\mu_{T_{b}}$ at HIRS $11 \mu \mathrm{m}$

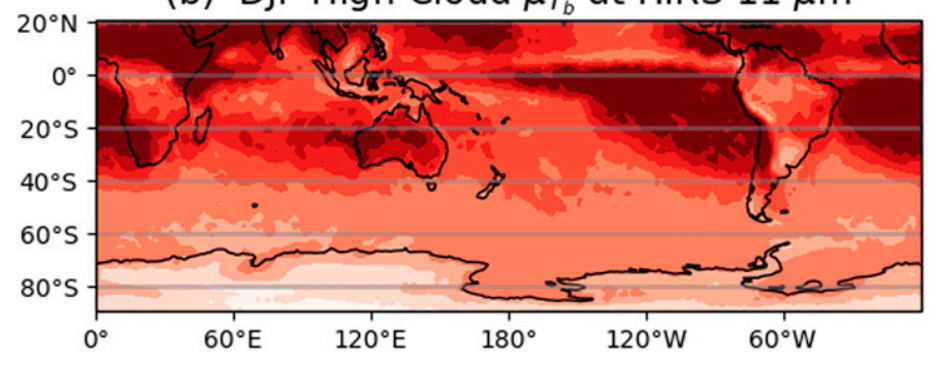

(c) DJF All Cloud $\sigma_{T_{b}}$ at HIRS $11 \mu \mathrm{m}$

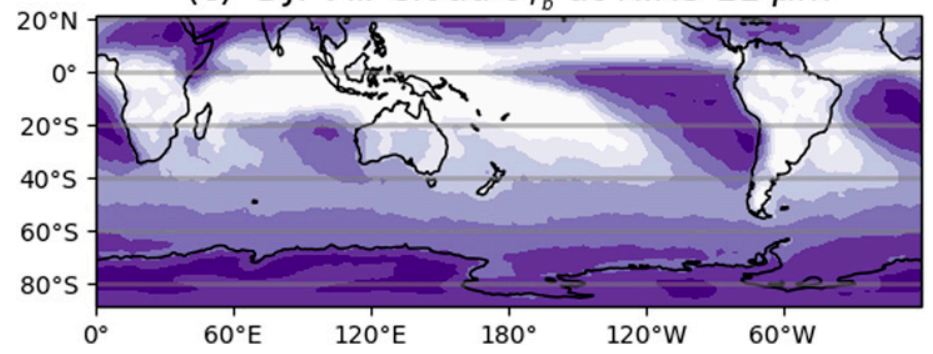

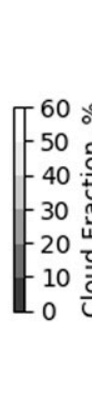

(d) $\overline{C F}, \overline{\mu_{T_{b}}} \& \overline{\sigma_{T_{b}}}$

FIG. 1. Austral summer (DJF) climatological (a) high-cloud fraction (HCF), (b) high cloud mean brightness temperature $\mu\left(T_{b}\right)$, and (c) brightness temperature standard deviation $\sigma\left(T_{b}\right)$ as observed in the HIRS window channel $(11 \mu \mathrm{m})$ for all clouds (as determined from AVHRR). (d) The zonal means of the climatologies, labeled with the actual boundary values at the bottom.

fraction regression using simulated ISCCP cloud fractions from reanalyses in the appendix.

As a measure of statistical significance, we perform a Monte Carlo bootstrapping test, repeating our regressions on 1000 random (in time) halves of the data, with replacement. In this work, we present the median values of each such regression. We also use stippling to represent grid points where more than 900 of the 1000 regressions yield coefficients of the same sign. Where appropriate, we present the zonal means of regressed fields. For comparison with previous work, we also regress zonal mean fields onto SAM and ENSO. In each case, we explicitly state which method we used. We regress all cloud statistical moment time series for all four seasons but focus on DJF for the purposes of this work.

\section{Results and discussion}

Here we present the results of our regression analysis of CF, $\mu\left(T_{b}\right)$, and $\sigma\left(T_{b}\right)$ onto SAM and MEI. We then compare and contrast our findings with other recent studies. In the appendix, we use reanalyses to shed light on discrepancies between studies.

\section{a. Climatology of austral summer cloudiness}

The climatology of high-cloud fraction (HCF) yielded by our interpolation method in Fig. 1a generally matches the HIRS-only climatology from Wylie et al. (2005) (Fig. 1). The highest climatological HCF is found in the tropics, with a maximum over the Maritime Continent, near the western Pacific warm pool. The low HCF belts between $20^{\circ} \mathrm{S}$ and $40^{\circ} \mathrm{S}$ coincide with climatological 
(a) DJF corr(HCF, all-cloud $\sigma T_{b}$ )

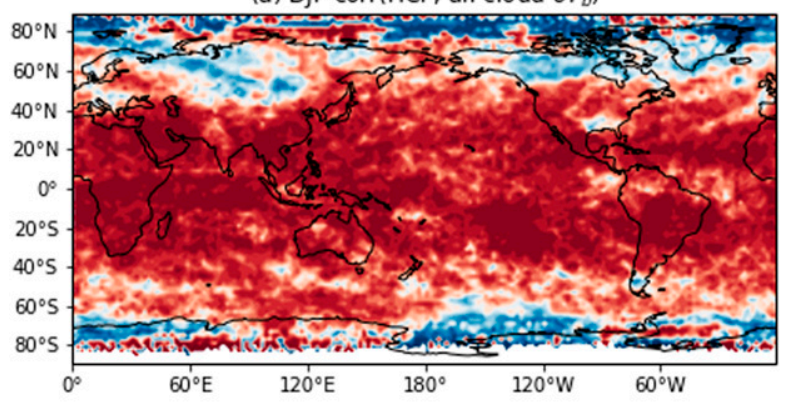

(b) DJF corr(HCF, all-cloud $\mu T_{b}$ )

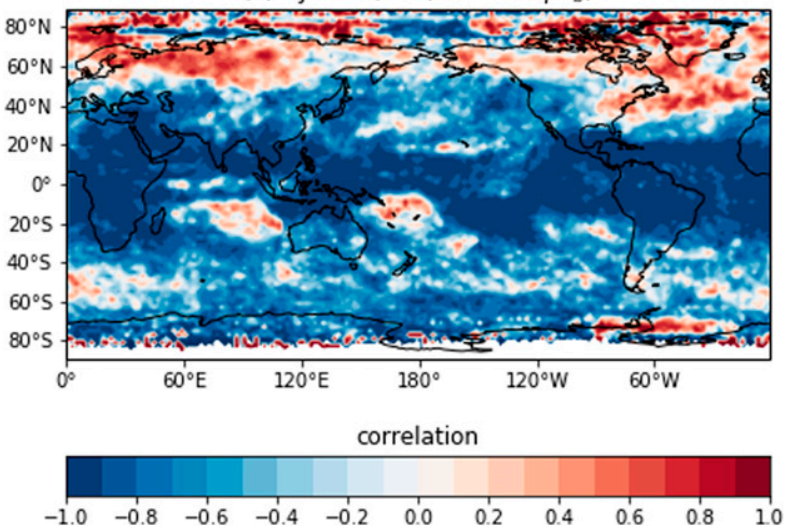

FIG. 2. Year-to-year correlation (a) between high-cloud fraction (HCF) and all-cloud brightness temperature standard deviation $\sigma T_{b}$, and (b) between HCF and all-cloud mean brightness temperatures $\mu T_{b}$, for austral winter (DJF).

subsidence in the vicinity of the subtropical ridge and the descending branch of the Hadley cell. The zonal mean HCF (Fig. 1d, black curve) has a good agreement with the weighted high cloud-top pressure in Marvel et al. (2015). The northwest-southeast-oriented cloud fraction maxima in the west Pacific collocate with the SPCZ (van der Wiel et al. 2015) while the lack of cloudiness in the southeast tropical-subtropical Pacific coincides with the southeast Pacific stratus cloud deck (Xu et al. 2005) and climatological high static stability (Klein and Hartmann 1993; Wood and Hartmann 2006).

Note that, in the tropics and subtropics, there is an east-to-west correspondence between $\mathrm{HCF}, \mu\left(T_{b}\right)$, and $\sigma\left(T_{b}\right)$; that is, higher high-cloud fractions coincide with colder $\mu\left(T_{b}\right)$ (Fig. 1b) and higher $\sigma\left(T_{b}\right)$ (Fig. 1c). The reverse is also true. This relationship is even stronger for the regression patterns we examine in sections $3 c(1)$ and $3 c(2)$. S16 note this relationship for a region within the northeast Pacific for two specific years. Below, we demonstrate the relationship for the globe during the operational history of $\mathrm{Met} O \mathrm{p}-\mathrm{A}$.

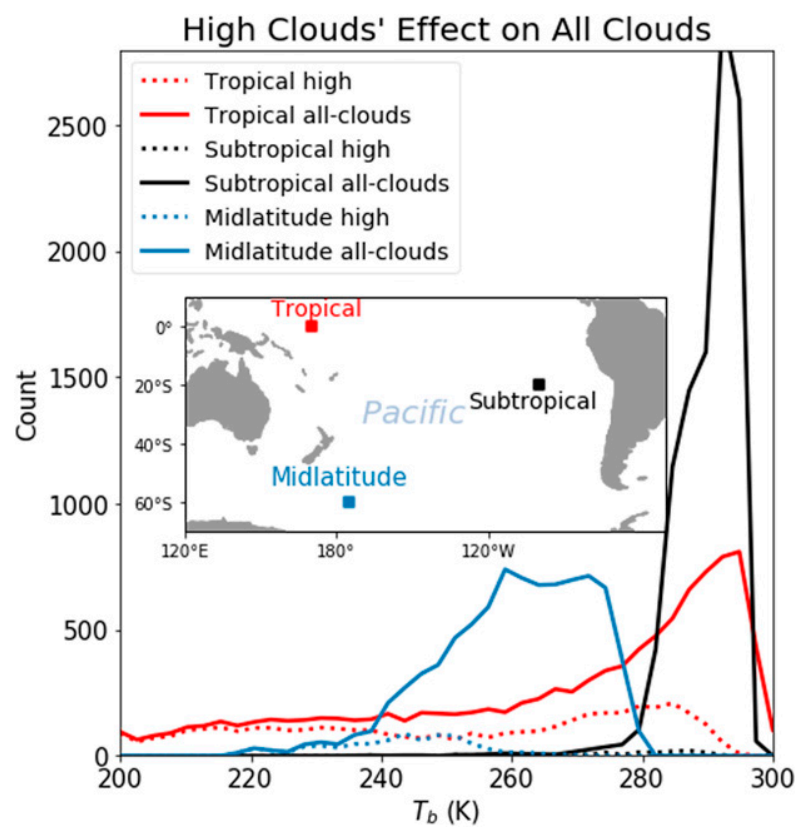

FIG. 3. HIRS channel $8(11.1 \mu \mathrm{m})$ brightness temperature histograms for cloudy pixels at a tropical location $\left(0^{\circ}, 170^{\circ} \mathrm{E} ; \pm 6^{\circ}\right.$ square; red), a subtropical location $\left(20^{\circ} \mathrm{S}, 100^{\circ} \mathrm{W} ; \pm 6^{\circ}\right.$ square; black), and a midlatitude location $\left(60^{\circ} \mathrm{S}, 175^{\circ} \mathrm{W} ; \pm 6^{\circ}\right.$ square; blue). Shown for all-cloud pixels (solid) and high-cloud-only pixels (dotted) for January 2015.

\section{b. On high-cloud fraction and all-cloud $\sigma\left(T_{b}\right)$}

The spatial correlation between HCF and all-cloud $\sigma\left(T_{b}\right)$ is moderate in the climatology, but the temporal correlation is high almost everywhere between $60^{\circ} \mathrm{S}$ and $60^{\circ} \mathrm{N}$ (Fig. 2a). The correlation between HCF and allcloud $\mu\left(T_{b}\right)$ (Fig. $\left.2 \mathrm{~b}\right)$ is similarly strong (albeit negative) over most of the globe, but there are regions in the southern subtropics where the sign of the correlation reverses.

Our explanation for the similarity between the HCF and $\sigma\left(T_{b}\right)$ fields is that high clouds constitute the cold tails of window-channel $T_{b}$ distributions (see Fig. 3). In the subtropical eastern Pacific (Fig. 3, black curves), for example, almost all of the brightness temperatures are warm, and the all-cloud $\sigma\left(T_{b}\right)$ is correspondingly low (see Fig. 1a). In the western Pacific warm pool (Fig. 3, red curves), brightness temperatures run the gamut from very warm to very cold, with the cold tail of the histogram being dominated by high clouds (the dotted red curve). Both the tropical and subtropical brightness temperature distributions have a very warm mode. Because these distributions have a warm mode, an increase in the frequency of cold brightness temperatures will increase the spread of the data. In other words, increased HCF will increase $\sigma\left(T_{b}\right)$. 
(a) DJF HCF Regressed onto SAM

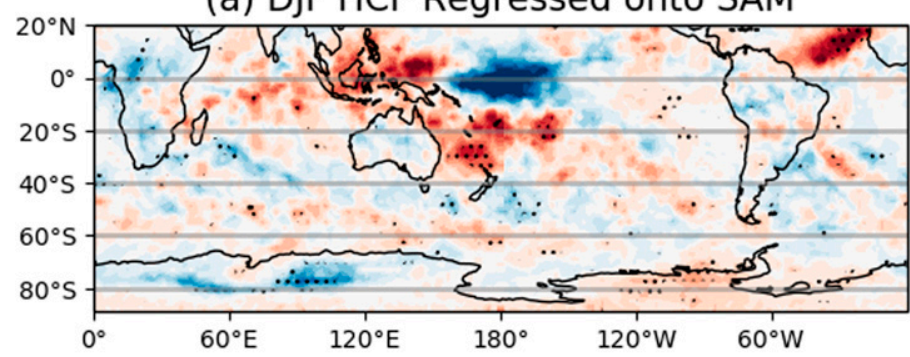

(b) DJF High Cloud $\mu_{T_{b}}$ at HIRS $11 \mu \mathrm{m}$ vs SAM

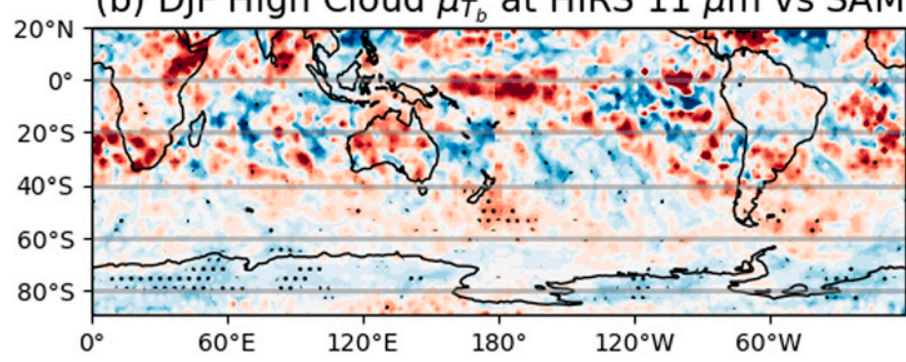

(c) DJF All Cloud $\sigma_{T_{b}}$ at HIRS $11 \mu \mathrm{m}$ vs SAM

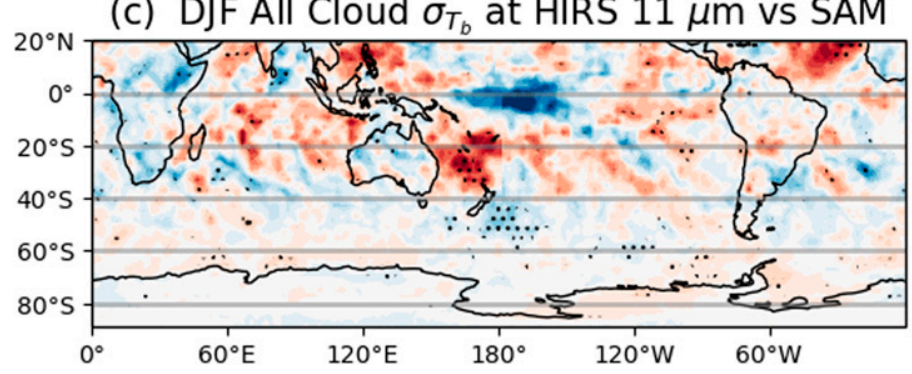

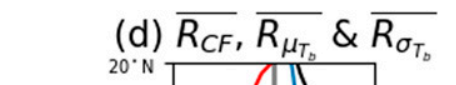

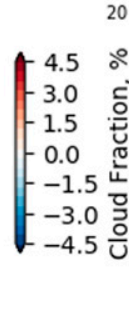

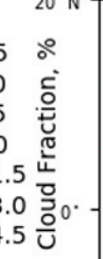
$\overline{R_{C F}}$
$\overline{R_{\mu_{s}}}$
$\overline{R_{\sigma_{t_{b}}}}$
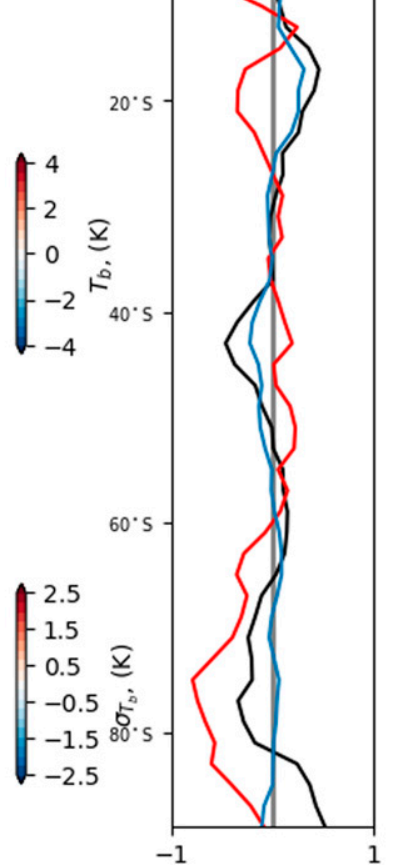

FIG. 4. Regressions of (a) high cloud fraction, (b) high cloudy pixel $\mu\left(T_{b}\right)$, and (c) all-cloud $\sigma\left(T_{b}\right)$ over the SH during austral summer (DJF) onto SAM. Stippling denotes $90 \%$ confidence based on Monte Carlo bootstrapping. (d) Zonal mean regressions on SAM for HCF (black), $\mu\left(T_{b}\right)$ (red), and $\sigma\left(T_{b}\right)$ (blue).

In the midlatitudes, the correlation is weaker. In the Southern Ocean (Fig. 3, blue curves), high clouds constitute the cold tail of the brightness temperature distribution, but they are closer to the mode of the distribution, and an increase in HCF will only have a moderate impact on the spread, or on the $\sigma\left(T_{b}\right)$.

Note that an increase in HCF does not necessarily imply an increase in the spread of the high-cloud-only brightness temperature statistics, but rather an increase in the sample size. That is, the distributions we have just examined do not provide any a priori reason to expect $\mathrm{HCF}$ and high-cloud $\sigma\left(T_{b}\right)$ to be related. That said, such a relationship empirically exists (not shown); the correlation, however, is about half that between HCF and all-cloud $\sigma\left(T_{b}\right)$, and it does not hold everywhere, even in the tropics. For this reason, the rest of our study makes use of the all-cloud $\sigma\left(T_{b}\right)$ field.

\section{c. Regression analyses}

\section{1) REgRESSIONS ONTO THE SAM}

Over southern middle and high latitudes, the leading mode of atmospheric variability (after the seasons) is the SAM. Previous literature (Grise et al. 2013; L16; Ceppi and Hartmann 2015) has examined the relationship between the SAM and its associated CF anomalies in ISCCP and CloudSat data. In the present study, we document the regional relationship between the SAM and its associated changes of CF from AVHRR and brightness temperature statistics from HIRS.

HCF regressions onto SAM (Fig. 4a) reveal the expected poleward shift of high clouds during the positive phase. Specifically, high clouds decrease over most longitudes at about $40^{\circ} \mathrm{S}$ (cf. Figs. $4 \mathrm{a}$ and 1a) and increase between $50^{\circ}-60^{\circ} \mathrm{S}$, consistent with Grise et al. 
(2013) (hereafter G13). From region to region, this poleward shift is apparent in $\sigma\left(T_{b}\right)$ (Fig. 4c), but not in $\mu\left(T_{b}\right)$ (Fig. $4 \mathrm{~b}$ ). Poleward of $70^{\circ} \mathrm{S}$, we observe mixed HCF regressions (Fig. 4a), and mostly cold $\mu\left(T_{b}\right)$ anomalies (Fig. 4b). Cloud-type information poleward of $70^{\circ} \mathrm{S}$ becomes increasingly suspect as the solar zenith angle decreases and snow and ice cover increase, but the combination of HCF and $\mu\left(T_{b}\right)$ seems to suggest an increase in cloudiness near the pole during the positive SAM phase. This is more in line with G13 than L16, who highlight a positive-negative dipole about $70^{\circ} \mathrm{S}$. We investigate this apparent discrepancy more closely in the appendix.

In addition to the overall meridional shifts, the SAM index is associated with opposing shifts in the South Atlantic convergence zone (SACZ), extending southeastward from the Amazon basin, and South Pacific convergence zone (SPCZ; see van der Wiel et al. 2015), extending southeastward from the Maritime Continent. The positive HCF regressions and negative $\mu\left(T_{b}\right)$ regressions show a dipole aligned with SACZ during positive SAM phase suggests an equatorward shift of the SACZ, in agreement with Rosso et al. (2018). The dipole structure over this region is more pronounced when regressed with monthly sampled DJF data. In contrast, the HCF and $\mu\left(T_{b}\right)$ anomalies on the poleward side of the SPCZ suggest a poleward shift there.

Near $40^{\circ} \mathrm{S}$, dipoles in the Indian and Pacific Oceans indicate a decrease in cloudiness in the descending branches of well-defined regional Hadley circulations. These low HCF anomalies may be associated with expected year-toyear shifts in the regional Hadley cell edge associated with coupled and uncoupled variability (Staten et al. 2019).

At higher latitudes, regression anomalies resemble a more zonally uniform meridional dipole, reminiscent of a poleward shift in cloudiness often associated with the jet. This dipole is strongest in the neighborhood of a cyclogenesis region over Patagonia (Hoskins and Karoly 1981; Hoskins and Hodges 2005).

These HCF and $\mu\left(T_{b}\right)$ anomalies can likewise be seen in the all-cloud $\sigma\left(T_{b}\right)$ regressed onto SAM (Figs. 4c,d). As with the climatological fields, the spatial correlation between the HCF regression map (Fig. 4a) and $\sigma\left(T_{b}\right)$ regression map (Fig. 4c) is high (0.74) for the map domain. The spatial correlation between the HCF regression map and the high-cloud $\sigma\left(T_{b}\right)$ is only 0.18 . Spatial correlations specifically over the $30^{\circ} \mathrm{S}$ poleward are similar, at 0.76 [for all-cloud $\sigma\left(T_{b}\right)$ ] and 0.14 [for highcloud $\sigma\left(T_{b}\right)$ ].

\section{2) REGRESSIONS ONTO ENSO}

The impacts of ENSO on interannual variability are profound. Here we examine ENSO's imprint on HIRS
$T_{b}$ statistics as with the SAM in section $3 \mathrm{c}(1)$. In a manner qualitatively opposite to the SAM regression, HCF and $T_{b}$ statistic regressions (Fig. 5) exhibit a southwestnortheast dipole in the western tropical Pacific, indicative of the shift in the climatological convective high cloud cluster north of Australia (Fig. 1a). In the zonal mean (Fig. 5d), one can see a contraction of the climatological HCF field into the deep tropics as this region warms and as convection intensifies there (Zelinka and Hartmann 2011; Ramanathan and Collins 1991). In westcentral tropical Pacific, the diagonal distribution of tropical high clouds associated with SPCZ shifts northeastward, consistent with the tropical contraction during El Niño episodes. Over Australia, HCF changes little with ENSO, but high $T_{b}$ anomalies occur along the Australian coastline, and elsewhere in Oceania. Over South America, El Niño brings about increased subsidence in northern Brazil and ascent in southern Brazil and Uruguay (Li et al. 2017; Zhou and Lau 2001; Grimm 2003), indicating a poleward shift of convective clouds over the continent. Regressions onto eastern Pacific and central Pacific ENSO indices (not shown) are similar.

While the regressions onto MEI discussed above focus on the tropics and subtropics, it is worth noting that high cloud fractions in middle and high latitudes also regress onto MEI as with SAM (note the difference in color scales between Figs. 4 and 5). But whereas the SAM is associated with a poleward shift of HCF anomalies, ENSO is generally associated with an equatorward shift. Thus, in the middle latitudes, and in regions near the Pacific warm pool, the MEI and SAM regressions mirror each other; in other regions they look nothing like one another. To quantify the relationship between the MEI and the SAM is beyond the scope of this work, but L'Heureux and Thompson (2006) showed that ENSO explains about $25 \%$ of the temporal variability in SAM.

As with the SAM regressions, the same patterns seen in the HCF and $\mu\left(T_{b}\right)$ MEI regressions are reflected in the $\sigma\left(T_{b}\right)$ anomalies (Fig. 5c). Here, the spatial correlation between $\mathrm{HCF}$ and all-pixel $\sigma\left(T_{b}\right)$ is 0.89 , and that between $\mathrm{HCF}$ and high-cloud $\sigma\left(T_{b}\right)$ is 0.50 for the map domain. (For the SH only, the correlations are 0.88 and 0.47 , respectively. For $15^{\circ} \mathrm{S}-15^{\circ} \mathrm{N}$ only, the correlations are 0.90 versus 0.57 .)

\section{Discussion}

This work carefully examines the fingerprints of Southern Hemispheric annular mode and ENSO on monthly interpolated AVHRR-HIRS cloud-type specific brightness temperature data. Our results generally concur with other studies on the relationship between cloudiness and large-scale circulation changes in that 
(a) DJF HCF Regressed onto MEI

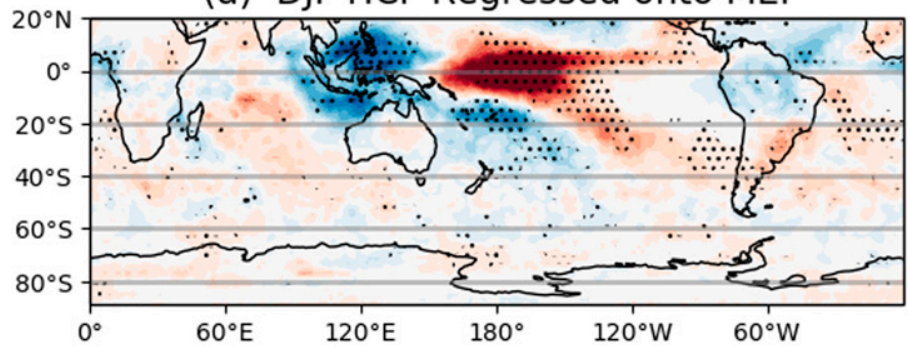

(b) DJF High Cloud $\mu_{T_{b}}$ at HIRS $11 \mu \mathrm{m}$ vs MEI

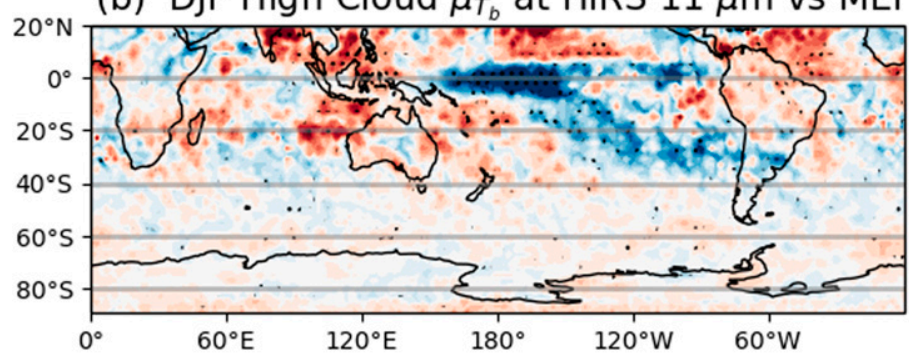

(c) DJF All Cloud $\sigma_{T_{b}}$ at HIRS $11 \mu \mathrm{m}$ vs MEI

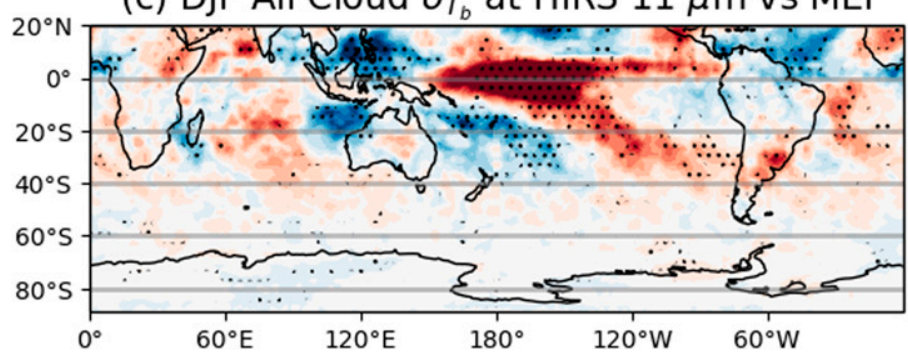

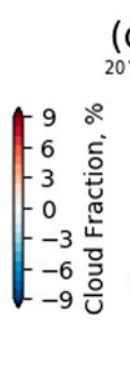

(d) $\overline{R_{C F}}, \overline{R_{\mu_{T_{s}}}} \& \overline{R_{\sigma_{T_{b}}}}$

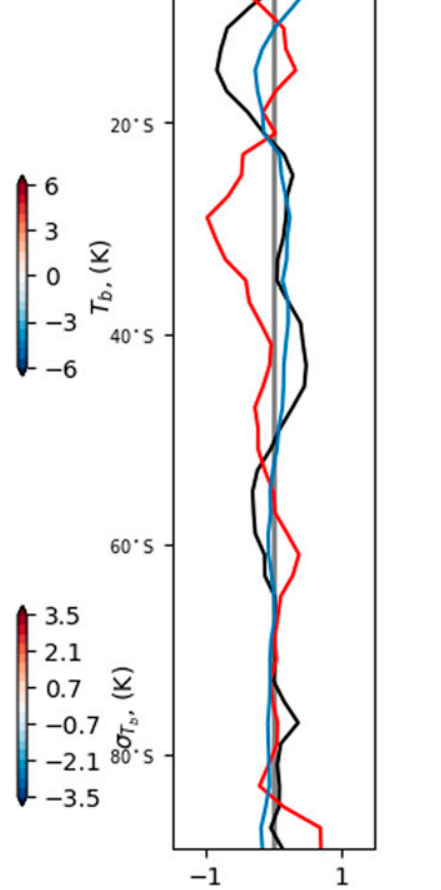

FIG. 5. As in Fig. 4, but for regressions on MEI; note that the contour levels differ from Fig. 4 by a factor of 3.

high clouds can be seen shifting poleward with the eddydriven jet. But even though studies agree on the zonal mean widening in the midlatitudes, in the subtropics the high-cloud fraction regression patterns seen in our study (as well as in L16 and G13) differ from the regional cloudiness trends in Fig. 1 of Norris et al. (2016). Granted, they analyze regional patterns of total cloudiness, but much of their observed changes in the middle and high latitudes occur at upper levels, suggesting that the regional increases are comparable to our high-cloud increases. With this in mind, we point out that the annual-mean high-cloud response to El Niño is opposite to the expansion trend from Norris et al. (2016) between the Indian and western Pacific Oceans (i.e., in the warm pool region). In other words, the cloudiness trend in Norris et al. (2016) resembles the high-cloud response to La Niña (not shown), but mainly in the Eastern Hemisphere. Meanwhile, the annual-mean high-cloud regression onto the SAM (not shown) resembles the cloudiness trend in Norris et al. (2016), but mainly in the
Western Hemisphere. The comparison lends observational support to the idea that the trend in subtropical circulation is distinct from the regional pattern of yearto-year circulation variability (see also Staten et al. 2019).

Future work may leverage brightness temperature statistics from the HIRS window channel to study changes in high-cloud fraction in the tropics and subtropics, which are responsible for much of the longwave cloud radiative forcing. The correlations between HCF and $\sigma\left(T_{b}\right)$ are positive and over 0.5 almost everywhere in the tropics and subtropics. S16 noted that $\sigma\left(T_{b}\right)$ seemed less sensitive than $\mu\left(T_{b}\right)$ to the choice of satellite. While the correlation between HCF and $\mu\left(T_{b}\right)$ is also strong, it flips sign over several large regions in the southern subtropics. In addition, changes in $\mu\left(T_{b}\right)$ are difficult to constrain with the extant satellite record, due to prelaunch and postlaunch instrument differences, and instrument drift. In contrast, contributions to $\sigma\left(T_{b}\right)$ from noise and instrument degradation are routinely 
(a) DJF, ERAI 2007 to 2010

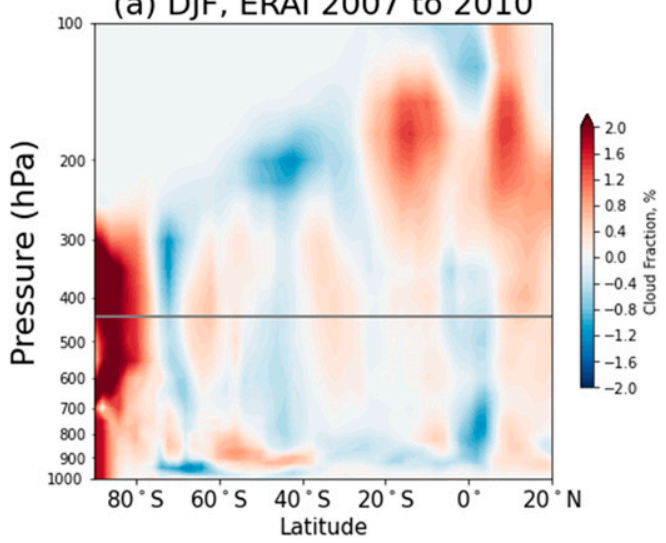

(b) DJF, ERAI 1979 to 2011

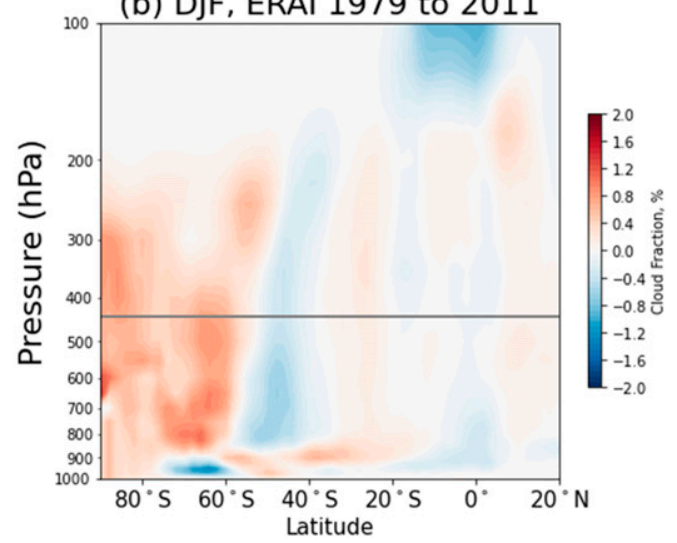

FIG. A1. Zonally averaged ERAI cloud fractions at 37 pressure levels regressed onto SAM in the Southern Hemisphere during DJF, for the "Li" (2007-10) and "Full" (1979-2011) periods. The horizontal gray line indicates the high cloud cut-off defined by ISCCP dataset.

monitored. The contribution to the variance by instrument degradation, then, should be readily calculable and accounted for, since $\sigma_{\text {measured }}^{2}=\sigma_{\text {instrument }}^{2}+\sigma_{\text {sample }}^{2}$ (and since, in all but the most severe cases of HIRS instrument degradation, $\sigma_{\text {instrument }}^{2} \ll \sigma_{\text {measured }}^{2}$ ). The expected stability and the demonstrated climate relevance of the HIRS window channel $\sigma\left(T_{b}\right)$ in the tropics and subtropics suggest a tantalizing avenue for future studies of cloud trends.

Acknowledgments. We thank two anonymous reviewers for their insightful and constructive comments during the preparation of this manuscript. This project was supported by NASA's Making Earth Science Data Records for Use in Research Environments (MEaSUREs) program (NNH17ZDA001N). The methods and data used in this study were initially supported by the NASA Satellite Calibration Interconsistency Studies program under Grant NNN13D968T directed by Lucia Tsaoussi. Dr. Kahn's contribution was performed at JPL-Caltech under contract with NASA. We thank the NOAA Comprehensive Large Array-data Stewardship System (CLASS) for providing the satellite data, Dr. Gareth Marshall for station-based SAM index data, NOAA Earth System Research Laboratory for MEI data, and ECMWF and NASA for reanalysis data. We also thank Cooperative Institute for Meteorological Satellite Studies (CIMSS) for the assistance in CLAVR-x software, Indiana University for the computing and storage services.

\section{APPENDIX}

\section{Comparison with Reanalyses}

In section 1 , we mention a discrepancy between regressions of Antarctic HCF onto SAM in our study (and in G13) and those of L16. L16 suggested that the discrepancy with earlier studies (in particular G13) may be due to the dataset used (CloudSat in L16, and ISCCP in G13), the analysis technique (in particular the 440-hPa cutoff for high clouds in ISCCP), differences raised by using pentad-mean or monthly-mean, and the surfacebased or all tropospheric level-based SAM index. Here we use reanalyses to confirm the importance of the choice of high-cloud threshold, but also to highlight the importance of the time period analyzed.

The reanalysis data we use for this comparison include the following:

- ERA-Interim. To help validate our results calculated from legacy satellites, and to reconcile perceived differences between earlier studies, we use monthly mean vertically resolved cloud fraction data from the European Centre for Medium-Range Weather Forecasts (ECMWF) ERA-Interim (ERAI) reanalysis (Simmons et al. 2006; Dee et al. 2011). Specifically, we use ERAI data with a horizontal resolution of $2^{\circ} \times 2^{\circ}$ and 37 pressure levels, spanning the years 1979-2016. We use the vertically resolved cloud fraction data for comparison with CloudSat data from L16. For comparison with the high cloud fields in S16, we calculate high cloud fractions as the maximum of level-by-level cloud fraction above the 440-hPa pressure level. (This amounts to assuming clouds overlap when possible, although our results are similar if random overlap is assumed.) Since we average our monthly data seasonally, for the L16 time period, we actually use data from December 2006-November 2010.

- MERRA-2. To ensure that our results from ERAI are not highly dependent on the choice of dataset, we repeat our analyses using data from the National Aeronautics and Space Administration (NASA) Modern-Era 

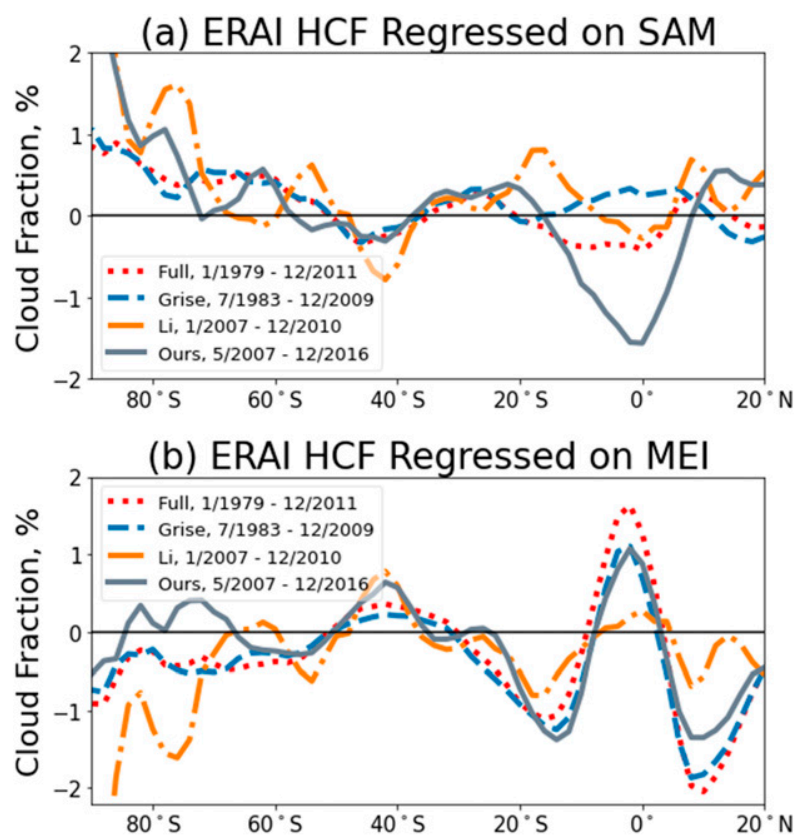

(c) HCF vs SAM, 5/2007-12/2016

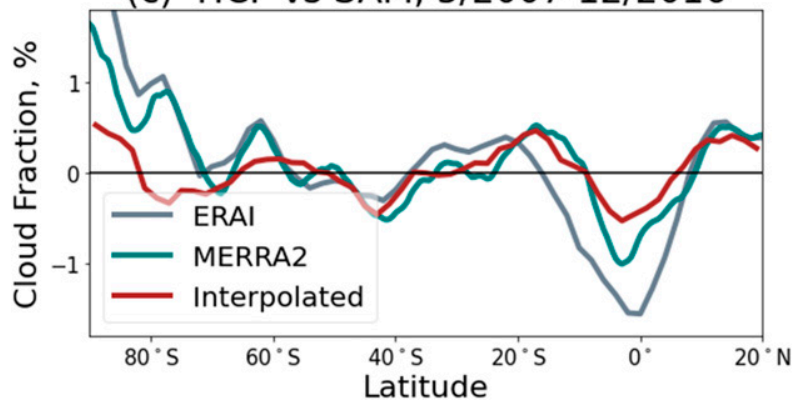

FIG. A2. Zonally averaged ERA-Interim high cloud fractions onto SAM and MEI in the Southern Hemisphere during different time periods.

Retrospective Analysis for Research and Applications, version 2 (MERRA-2) (Bosilovich et al. 2015). Specifically, we used monthly averaged MERRA-2 data with a horizontal resolution of $2^{\circ} \times 2^{\circ}$ and 42 vertical levels, spanning the years $2007-16$.

In L16, a meridional dipole in the regression of uppertropospheric high cloud incidence onto SAM was detected with both CloudSat and ERAI. They noted a positive polarity at $50^{\circ} \mathrm{S}$ and a negative polarity at $70^{\circ} \mathrm{S}$ (see their Figs. A1a-c and B1a), and compared this with the ISCCP high cloud fraction regressions on SAM by G13 (see their Fig. 3), who found no such dipole structure. To test the role of the time period and vertical cutoff, we reproduce Figs. A1b and A1c from L16 using ERAI cloud fraction data from 2007-10 (Fig. A1a herein), but we repeat the analysis for 1979-2011 (Fig. A1b herein) during DJF. (Results for the annual mean are similar, albeit weaker.)

Both time periods exhibit the negative polarity at $70^{\circ} \mathrm{S}$, but the dipole is much weaker and confined to upper levels-around $300 \mathrm{hPa}$-in the 1979-2011 average. If one uses the 440-hPa cutoff as in G13, then no dipole would be detected using the reanalysis time period 1979-2011. The strong dipole in L16 thus appears to result from 1) the particular time period they analyze and 2) the 7-km threshold they use for high clouds. Changing either can weaken the dipole and changing both can remove it altogether.

To diagnose the sensitivity of the dipole to the time period and dataset examined, we regress the zonal HCF from reanalyses during several time periods onto the SAM and ENSO indices (Fig. A2a). In contrast to the robust meridional cloud shift between $45^{\circ} \mathrm{S}$ (negative) and $60^{\circ} \mathrm{S}$ (positive), the dipole at $70^{\circ} \mathrm{S}$ is sensitive to the time period examined, with the strongest dipole occurring during 2007-16 (Fig. A2a, solid line labeled "Ours"). This time period saw a shift in ENSO from negative to positive at this latitude, suggesting the dipole seen in our SAM regression may have been interference by El Niño. But the MEI regression (Fig. A2b) behaves similarly to the SAM regression, in that it is most robust at and equatorward of $60^{\circ} \mathrm{S}$. Poleward of $60^{\circ} \mathrm{S}$, the two longest time periods and the shortest time period stay negative while the second shortest period ("Ours") becomes positive.

Our analysis above is purely based on reanalyses and does not discount the possibility that a meridional HCF dipole about $70^{\circ} \mathrm{S}$ is real in time periods other than 200716. As a final check of dataset dependency, we regress high-cloud fraction from our interpolated dataset and from two reanalyses all onto the SAM during the same time period (Fig. A2c). As for the ENSO and SAM regressions across different time periods, the zonal regressions agree well with each other equatorward of about $55^{\circ} \mathrm{S}$. From $55^{\circ} \mathrm{S}$ poleward, the interpolated dataset stands out as being the only dataset to have a meridional dipole in $\mathrm{HCF}$ regression anomalies. (Note that the interpolated data used in this study begin several months after the time period in L16, precluding a precise determination of the role of time period for our dataset.) Of course, the high-cloud regression pattern on MEI and SAM depends on the time period studied. Reanalyses suggest that perceived discrepancies in SAM-related high-cloud anomalies around $70^{\circ} \mathrm{S}$ in L16 and G13 can be explained by a combination of the time period examined and the high-cloud height threshold chosen. But if our interpolated dataset is to be trusted, reanalyses may not realistically represent the meridional dipole around $70^{\circ} \mathrm{S}$ in general. Studies combining data 
from multiple satellites would more definitively determine the regional cloud patterns associated with SAM and ENSO. This in turn would complement numerical attribution studies of the circulation and cloud response to individual forcings and modes of variability.

\section{REFERENCES}

Anderson, J., J. Dykema, R. Goody, H. Hu, and D. Kirk-Davidoff, 2004: Absolute, spectrally-resolved, thermal radiance: A benchmark for climate monitoring from space. J. Quant. Spectrosc. Radiat. Transfer, 85, 367-383, https://doi.org/10.1016/ S0022-4073(03)00232-2.

Bender, F. A.-M., V. Ramanathan, and G. Tselioudis, 2012: Changes in extratropical storm track cloudiness 1983-2008: Observational support for a poleward shift. Climate Dyn., 38, 2037-2053, https://doi.org/10.1007/s00382-011-1065-6.

Bosilovich, M. G., and Coauthors, 2015: MERRA-2: Initial evaluation of the climate. NASA Tech. Memo. NASA/TM-2015-104606/Vol. 43 145 pp., https://gmao.gsfc.nasa.gov/pubs/docs/Bosilovich803.pdf.

Boucher, O., and Coauthors, 2013: Clouds and aerosols. Climate Change 2013: The Physical Science Basis, T. F. Stocker et al., Eds., Cambridge University Press, 571-657.

Ceppi, P., and D. L. Hartmann, 2015: Connections between clouds, radiation, and midlatitude dynamics: A review. Curr. Climate Change Rep., 1, 94-102, https://doi.org/10.1007/s40641-015-0010-x.

Choi, M., and B. Sweetman, 2010: Efficient calculation of statistical moments for structural health monitoring. Struct. Health Monit., 9, 13-24, https://doi.org/10.1177/1475921709341014.

Dee, D. P., and Coauthors, 2011: The ERA-Interim reanalysis: Configuration and performance of the data assimilation system. Quart. J. Roy. Meteor. Soc., 137, 553-597, https://doi.org/ 10.1002/qj.828.

Eastman, R., and S. G. Warren, 2013: A 39-yr survey of cloud changes from land stations worldwide 1971-2009: Long-term trends, relation to aerosols, and expansion of the tropical belt. J. Climate, 26, 1286-1303, https://doi.org/10.1175/JCLI-D-12-00280.1.

Evan, A. T., A. K. Heidinger, and D. J. Vimont, 2007: Arguments against a physical long-term trend in global ISCCP cloud amounts. Geophys. Res. Lett., 34, L04701, https://oi.org/ 10.1029/2006GL028083.

Foster, M. J., and A. Heidinger, 2013: PATMOS-x: Results from a diurnally corrected 30-yr satellite cloud climatology. J. Climate, 26, 414-425, https://doi.org/10.1175/JCLI-D-11-00666.1.

, - M. Hiley, S. Wanzong, A. Walther, and D. Botambekov, 2016: PATMOS-x cloud climate record trend sensitivity to reanalysis products. Remote Sens., 8, 424, https://doi.org/10.3390/ rs 8050424.

Frey, R. A., S. A. Ackerman, and B. J. Soden, 1996: Climate parameters from satellite spectral measurements. Part I: Collocated AVHRR and HIRS/2 observations of spectral greenhouse parameter. J. Climate, 9, 327-344, https://doi.org/10.1175/15200442(1996)009<0327:CPFSSM > 2.0.CO;2.

Fyfe, J. C., 2003: Separating extratropical zonal wind variability and mean change. J. Climate, 16, 863-874, https://doi.org/ 10.1175/1520-0442(2003)016<0863:SEZWVA $>2.0 . C O ; 2$.

Gillett, N. P., T. D. Kell, and P. D. Jones, 2006: Regional climate impacts of the Southern Annular Mode. Geophys. Res. Lett., 33, L23704, https://doi.org/10.1029/2006GL027721.

Grimm, A. M., 2003: The El Niño impact on the summer monsoon in Brazil: Regional processes versus remote influences. J. Climate,
16, 263-280, https://doi.org/10.1175/1520-0442(2003)016<0263: TENIOT $>2.0 . \mathrm{CO} ; 2$.

Grise, K. M., L. M. Polvani, G. Tselioudis, Y. Wu, and M. D. Zelinka, 2013: The ozone hole indirect effect: Cloud-radiative anomalies accompanying the poleward shift of the eddydriven jet in the Southern Hemisphere. Geophys. Res. Lett., 40, 3688-3692, https://doi.org/10.1002/grl.50675.

Heidinger, A. K., M. J. Foster, A. Walther, and X. T. Zhao, 2014: The Pathfinder Atmospheres-Extended AVHRR climate dataset. Bull. Amer. Meteor. Soc., 95, 909-922, https://doi.org/ 10.1175/BAMS-D-12-00246.1.

_, _ D. Dotambekov, M. Hiley, A. Walther, and Y. Li, 2016: Using the NASA EOS A-Train to probe the performance of the NOAA PATMOS-x cloud fraction CDR. Remote Sens., 8 , 511, https://doi.org/10.3390/rs8060511.

Held, I. M., and B. J. Soden, 2006: Robust responses of the hydrological cycle to global warming. J. Climate, 19, 5686-5699, https://doi.org/10.1175/JCLI3990.1.

Hoskins, B. J., and D. J. Karoly, 1981: The steady linear response of a spherical atmosphere to thermal and orographic forcing. J. Atmos. Sci, 38, 1179-1196, https://doi.org/10.1175/1520-0469(1981)038<1179: TSLROA $>2.0 . \mathrm{CO} ; 2$.

, and K. I. Hodges, 2005: A new perspective on Southern Hemisphere storm tracks. J. Climate, 18, 4108-4129, https:// doi.org/10.1175/JCLI3570.1.

Japan Meteorological Agency, 2015: JRA-55AMIP: The Japanese 55year Reanalysis AMIP-type simulation. NCAR, Computational and Information Systems Laboratory Research Data Archive, accessed 2020, https://doi.org/10.5065/D6TB14ZD.

Kalnay, E., and Coauthors, 1996: The NCEP/NCAR 40-Year Reanalysis Project. Bull. Amer. Meteor. Soc., 77, 437-471, https://doi.org/ 10.1175/1520-0477(1996)077<0437:TNYRP > 2.0.CO;2.

Kiladis, G. N., and H. van Loon, 1988: The Southern Oscillation. Part VII: Meteorological anomalies over the Indian and Pacific sectors associated with the extremes of the oscillation. Mon. Wea. Rev., 116, 120-136, https://doi.org/10.1175/15200493(1988)116<0120:TSOPVM > 2.0.CO;2.

Klein, S. A., and D. L. Hartmann, 1993: The seasonal cycle of low stratiform clouds. J. Climate, 6, 1587-1606, https://doi.org/ 10.1175/1520-0442(1993)006<1587:TSCOLS $>2.0$. CO 2 .

_ B. J. Soden, and N.-C. Lau, 1999: Remote sea surface temperature variations during ENSO: Evidence for a tropical atmospheric bridge. J. Climate, 12, 917-932, https://doi.org/ 10.1175/1520-0442(1999)012<0917:RSSTVD>2.0.CO;2.

L'Heureux, M. L., and D. W. J. Thompson, 2006: Observed relationships between the El Niño-Southern Oscillation and the extratropical zonal-mean circulation. J. Climate, 19, 276-287, https://doi.org/10.1175/JCLI3617.1.

Li, J., W. W. Wolf, W. P. Menzel, W. Zhang, H.-L. Huang, and T. H. Achtor, 2000: Global soundings of the atmosphere from ATOVS measurements: The algorithm and validation. J. Appl. Meteor., 39, 1248-1268, https://doi.org/10.1175/1520-0450(2000) $039<1248:$ GSOTAF $>2.0 . \mathrm{CO} ; 2$.

Li, K.-F., H. Su, S.-N. Mak, T. M. Chang, J. H. Jiang, J. R. Norris, and Y. L. Yung, 2017: An analysis of high cloud variability: Imprints from the El Niño-Southern Oscillation. Climate Dyn., 48, 447-457, https://doi.org/10.1007/s00382-016-3086-7.

Li, Y., and D. W. J. Thompson, 2016: Observed signatures of the barotropic and baroclinic annular modes in cloud vertical structure and cloud radiative effects. J. Climate, 29, 4723-4740, https://doi.org/10.1175/JCLI-D-15-0692.1.

, - - Y. Huang, and M. Zhang, 2014: Observed linkages between the northern annular mode/North Atlantic Oscillation, 
cloud incidence, and cloud radiative forcing. Geophys. Res. Lett., 41, 1681-1688, https://doi.org/10.1002/2013GL059113.

Lu, J., G. A. Vecchi, and T. Reichler, 2007: Expansion of the Hadley cell under global warming. Geophys. Res. Lett., 34, L06805, https://doi.org/10.1029/2006GL028443.

- G. Chen, and D. M. W. Frierson, 2008: Response of the zonal mean atmospheric circulation to El Niño versus global warming. J. Climate, 21, 5835-5851, https://doi.org/10.1175/ 2008JCLI2200.1.

Marshall, G. J., 2003: Trends in the southern annular mode from observations and reanalyses. J. Climate, 16, 4134-4143, https:// doi.org/10.1175/1520-0442(2003)016<4134:TITSAM>2.0.CO;2.

Marvel, K., M. Zelinka, S. A. Klein, C. Bonfils, P. Caldwell, C. Doutriaux, B. D. Santer, and K. E. Taylor, 2015: External influences on modeled and observed cloud trends. J. Climate, 28, 4820-4840, https://doi.org/10.1175/JCLI-D-14-00734.1.

Menzel, W. P., R. A. Frey, E. E. Borbas, B. A. Baum, G. Cureton, and N. Bearson, 2016: Reprocessing of HIRS satellite measurements from 1980 to 2015: Development toward a consistent decadal cloud record. J. Appl. Meteor. Climatol., 55, 23972410, https://doi.org/10.1175/JAMC-D-16-0129.1.

Naud, C. M., J. F. Booth, and A. D. Del Genio, 2014: Evaluation of ERA-Interim and MERRA cloudiness in the Southern Ocean. J. Climate, 27, 2109-2124, https://doi.org/10.1175/JCLI-D-1300432.1.

Norris, J. R., and A. T. Evan, 2015: Empirical removal of artifacts from the ISCCP and PATMOS-x satellite cloud records. J. Atmos. Oceanic Technol., 32, 691-702, https://doi.org/ 10.1175/JTECH-D-14-00058.1.

—, R. J. Allen, A. T. Evan, M. D. Zelinka, C. W. O'Dell, and S. A. Klein, 2016: Evidence for climate change in the satellite cloud record. Nature, 536, 72-75, https://doi.org/10.1038/nature18273.

Radley, C., S. Fueglistaler, and L. Donner, 2014: Cloud and radiative balance changes in response to ENSO in observations and models. J. Climate, 27, 3100-3113, https://doi.org/10.1175/ JCLI-D-13-00338.1.

Ramanathan, V., and W. Collins, 1991: Thermodynamic regulation of ocean warming by cirrus clouds deduced from observations of the 1987 El Niño. Nature, 351, 27-32, https://doi.org/ 10.1038/351027a0.

Rivière, G., 2011: A dynamical interpretation of the poleward shift of the jet streams in global warming scenarios. J. Atmos. Sci., 68, 1253-1272, https://doi.org/10.1175/2011JAS3641.1.

Rosso, F. V., N. T. Boiaski, S. E. T. Ferraz, and T. C. Robles, 2018: Influence of the Antarctic Oscillation on the South Atlantic convergence zone. Atmosphere, 9, 431, https://doi.org/10.3390/atmos9110431.

Rossow, W. B., and R. A. Schiffer, 1991: ISCCP cloud data products. Bull. Amer. Meteor. Soc., 72, 2-20, https://doi.org/ 10.1175/1520-0477(1991)072<0002:ICDP > 2.0.CO;2.

$\longrightarrow$, and —, 1999: Advances in understanding clouds from ISCCP. Bull. Amer. Meteor. Soc., 80, 2261-2287, https://doi.org/ 10.1175/1520-0477(1999)080<2261:AIUCFI > 2.0.CO;2.

Schiffer, R. A., and W. B. Rossow, 1985: ISCCP global radiance data set: A new resource for climate research. Bull. Amer. Meteor. Soc., 66, 1498-1505, https://doi.org/10.1175/15200477(1985)066<1498:IGRDSA>2.0.CO;2.

Seager, R., N. Harnik, Y. Kushnir, W. Robinson, and J. Miller, 2003: Mechanisms of hemispherically symmetric climate variability. J. Climate, 16, 2960-2978, https://doi.org/10.1175/ 1520-0442(2003)016<2960:MOHSCV>2.0.CO;2.

Simmons, A., S. Uppala, D. Dee, and S. Kobayashi, 2006: ERAInterim: New ECMWF reanalysis products from 1989 onwards. ECMWF Newsletter, No. 110, 25-35, https://www.ecmwf.int/ sites/default/files/elibrary/2006/14615-newsletter-no110-winter200607.pdf.

Staten, P. W., B. H. Kahn, M. M. Schreier, and A. K. Heidinger, 2016: Subpixel characterization of HIRS spectral radiances using cloud properties from AVHRR. J. Atmos. Oceanic Technol., 33, 1519-1538, https://doi.org/10.1175/JTECH-D15-0187.1.

_ K. M. Grise, S. M. Davis, K. Karnauskas, and N. Davis, 2019: Regional widening of tropical overturning: Forced change, natural variability, and recent trends. J. Geophys. Res. Atmos., 124, 6104-6119, https://doi.org/10.1029/2018JD030100.

Thomas, S. M., A. K. Heidinger, and M. J. Pavolonis, 2004: Comparison of NOAA's operational AVHRR-derived cloud amount to other satellite-derived cloud climatologies. J. Climate, 17, 4805-4822, https://doi.org/10.1175/JCLI-3242.1.

Thompson, D. W. J., and J. M. Wallace, 2000: Annular modes in the extratropical circulation. Part I: Month-to-month variability. J. Climate, 13, 1000-1016, https://doi.org/10.1175/1520-0442(2000) 013<1000:AMITEC > 2.0.CO;2.

— nular variability in the Southern Hemisphere. J. Atmos. Sci., 71, 1480-1493, https://doi.org/10.1175/JAS-D-13-0185.1.

_ and Y. Li, 2015: Baroclinic and barotropic annular variability in the Northern Hemisphere. J. Atmos. Sci., 72, 1117-1136, https://doi.org/10.1175/JAS-D-14-0104.1.

van der Wiel, K., A. J. Matthews, D. P. Stevens, and M. M. Joshi, 2015: A dynamical framework for the origin of the diagonal South Pacific and South Atlantic convergence zones. Quart. J. Roy. Meteor. Soc., 141, 1997-2010, https://doi.org/10.1002/qj.2508.

Wolter, K., 1987: The Southern Oscillation in surface circulation and climate over the tropical Atlantic, eastern Pacific, and Indian Oceans as captured by cluster analysis. J. Climate Appl. Meteor., 26, 540-558, https://doi.org/10.1175/1520-0450(1987) $026<0540$ :TSOISC $>2.0$.CO;2.

- and M. S. Timlin, 1993: Monitoring ENSO in COADS with a seasonally adjusted principal component index. Proc. 17th Climate Diagnostics Workshop, Norman, OK, NOAA, 52-57. _ and _ 1998: Measuring the strength of ENSO events: How does 1997/98 rank? Weather, 53, 315-324, https://doi.org/ 10.1002/j.1477-8696.1998.tb06408.x.

Wood, R., and D. L. Hartmann, 2006: Spatial variability of liquid water path in marine low cloud: The importance of mesoscale cellular convection. J. Climate, 19, 1748-1764, https://doi.org/ 10.1175/JCLI3702.1.

Wylie, D. P., W. P. Menzel, H. M. Woolf, and K. I. Strabala, 1994: Four years of global cirrus cloud statistics using HIRS. J. Climate, 7, 1972-1986, https://doi.org/10.1175/ 1520-0442(1994)007<1972:FYOGCC >2.0.CO;2.

— D. L. Jackson, W. P. Menzel, and J. J. Bates, 2005: Trends in global cloud cover in two decades of HIRS observations. J. Climate, 18, 3021-3031, https://doi.org/10.1175/JCLI3461.1.

Xu, H., S.-P. Xie, and Y. Wang, 2005: Subseasonal variability of the southeast Pacific stratus cloud deck. J. Climate, 18, 131-142, https://doi.org/10.1175/JCLI3250.1.

Yin, J. H., 2005: A consistent poleward shift of the storm tracks in simulations of 21 st century climate. Geophys. Res. Lett., 32 , L18701, https://doi.org/10.1029/2005GL023684.

Zelinka, M. D., and D. L. Hartmann, 2011: The observed sensitivity of high clouds to mean surface temperature anomalies in the tropics. J. Geophys. Res., 116, D23103, https://doi.org/10.1029/2011JD016459.

Zhou, J., and K.-M. Lau, 2001: Principal modes of interannual and decadal variability of summer rainfall over South America. Int. J. Climatol., 21, 1623-1644, https://doi.org/10.1002/joc.700. 